\title{
Behaviour therapy and drug treatments for obsessive-compulsive disorder
}

\author{
C. Duggan
}

Three recent advances have increased the importance of obsessive-compulsive disorder (OCD) for the general psychiatrist. It is a more common disorder than previously realised, there are effective treatments, and the basic neurobiological substrate for the condition is being identified. This review will consider these advances but focus mainly on the practical aspects of assessing the condition and planning treatment.

\section{Diagnostic criteria}

OCD is an anxiety disorder, with the anxiety arising from certain cues which have to be neutralised either by a behavioural or mental ritual. Anxiogenic cues may be either thoughts or behaviours which the OCD sufferer has to undo with anxiolytic responses which, again, may be either thoughts or behaviours. Failure to carry out the 'undoing' ritual results in an increase in anxiety.

Obsessions are defined as recurrent and persistent ideas, thoughts or impulses which are experienced, at least initially, as intrusive and senseless. They commonly focus on thoughts of contamination, violence, doubting and worries about sexual or religious prohibitions. These are invariably distressing so an attempt is made to resist, suppress or neutralise them with some other thought or action. The individual recognises that these are the product of his or her own mind and not imposed from outside.

Compulsions are repetitive, purposeful and intentional behaviours which are performed in response to an obsession, or according to certain rules or in a stereotyped fashion. They frequently involve checking, washing and counting. The behaviour is designed to neutralise or to prevent discomfort from some dreaded event or situation. The person recognises the behaviour as excessive or unreasonable.

In addition to these phenomenological criteria, recent definitions also include the requirement that the obsessions or compulsions should cause distress, take up more than an hour a day and interfere with occupational or social functioning. Obsessional slowness refers to abnormal length of time spent in performing everyday tasks. This is usually secondary either to ruminating on whether a particular act has been carried out properly or to being abnormally indecisive.

\section{Associated features}

Secondary avoidance is common, with idiosyncratic thinking and the belief that the slightest infringement of the rules will spell catastrophe. This is often extensive and may result in the core anxiety feature of the disorder not being evident.

Family members are often forced to offer repeated reassurance and go to extraordinary lengths to comply with the avoidant behaviour. Thus, the impact of the disorder often extends far beyond the affected individual. Relatives often make useful allies in a treatment intervention.

Comorbidity often occurs with OCD, the most frequently found disorders are depression (30\%), other anxiety states, and drug misuse (frequently iatrogenic).

\section{Epidemiology}

OCD was regarded as an uncommon disorder with a lifetime prevalence rate of $0.1 \%$ before the recent 
epidemiological surveys. The ECA survey, for instance, showed rates of 2-3\% making OCD the fourth most common psychiatric disorder (Myers et al, 1984). The discrepancy between estimated and true rates suggests a hidden morbidity in the community. This perception is supported by the experience of specialised referral centres where there is often a delay of many years between the onset of the disorder and presentation.

Other epidemiological aspects of OCD include an equal sex ratio, although compulsive washing and obsessional slowness are more common among females and males respectively (Marks, 1987). The age of onset is in early adolescence or early adulthood although there is an interesting additional increase among females over 60 years of age. $O C D$ has a variable course with exacerbations often being precipitated by adverse life events (Rasmussen \& Eisen, 1992).

\section{Aetiology}

Current theories involve an interaction between biological vulnerability and social learning. Attention has focused on the orbito-frontal cortex, cingulate cortex and caudate nucleus and it is suggested that these form a hyperactive circuit in OCD (Insel, 1992). Of particular interest is Baxter et al's (1992) positron emission tomography scan finding that caudate nucleus activity decreased in OCD subjects treated with either fluoxetine or 10 weeks of behaviour therapy. These advances need to be integrated with the psychological models of how the avoidance and neutralising rituals prevent the extinction of conditioned anxiety.

\section{Assessment strategies}

In the assessment of OCD, a behavioural analysis provides a comprehensive examination of the disorder. This involves identification of the anxiogenic stimulus (usually the obsession), the resultant anxiety state and then the anxiolytic response. The anxiogenic stimulus may occur spontaneously or be cued by a number of stimuli which that individual will avoid to prevent its occurrence. The undoing ritual may be overt, in the form of a behaviour which is excessive, or covert, in the form of a mental ritual. As the ritual reduces anxiety, it has an important maintaining, reinforcing or even a pre-emptive function.

One should also establish the impact on the individual's relationships, and occupational functioning. The recruiting of an informant, such as a close family member, is often very useful in that the OCD sufferer may minimise his level of disability or omit crucial avoidances, and family members may need guidance in avoiding offering reassurance. This often involves explicit coaching, for example, encouraging the relative to respond to requests for reassurance with the same neutral and monotonous response - 'the hospital has instructed me to say no answer' (Marks, 1986).

One should inquire about previous treatments, their appropriateness, and the nature of the response. One also needs to assess daily drug and alcohol intake of the patient. No more than $5 \mathrm{mg}$ diazepam or 2 units of alcohol should be taken while doing the exposure therapy as this will affect habituation. Finally it is important to assess the mental state to decide if there is any depression or evidence of psychosis.

It is essential to check out continually that the formulation is in accord with the individual's own perception as, apart from the need to obtain accuracy, this will help cement the therapeutic alliance. Focusing on the presenting problem in considerable depth has therapeutic properties as well as being helpful in the assessment.

The therapist and patient together should also determine a list of specific targets which the patient wishes to achieve. These should be quantified and form a baseline whereby the impact of the therapy may be judged. There are several instruments which give a quantitative assessment of OCD symptoms. As a routine package in the assessment of OCD, I would advise using the Self-Report Obsessive Compulsive Checklist, (Marks, 1986); the Fear Questionnaire (Marks \& Matthews, 1979), and the Beck Depression Inventory (Beck et al, 1961).

\section{Differential diagnoses}

\section{Obsessional Compulsive Personality Disorder (OCPD)}

Conventionally, OCPD traits are considered egosyntonic (i.e. not distressing or alien) whereas OCD symptoms are egodystonic. This separation becomes difficult when the phenomena of OCD become embedded with such a degree of secondary avoidance that subjective distress becomes minimal and resistance to the intrusion disappears (Lelliott et al, 1988). Research has shown that many personality disorders other than OCPD co-occur with $O C D$ and this hampers the treatment of OCD with medication, behaviour treatment and with self-help methods in general. 


\section{Depression}

This is the most important and common cooccurrent condition with a lifetime prevalence of $70 \%$ in those with OCD; $25-30 \%$ of these are depressed at presentation (Rasmussen \& Eisler, 1988). Comorbid depression may cause an individual with longstanding OCD to present for treatment, may increase the severity of OCD and may reduce the response of OCD to treatment.

\section{Other anxiety states}

It may be difficult to distinguish an individual with a phobia from one with OCD (Marks, 1987). In addition, the co-occurrence of OCD with other anxiety states is common, with one study showing that other phobias and panic disorder occurred in $40 \%$ and $10 \%$ respectively of those with OCD (Mulder et al, 1991).

\section{OCD as a prelude to psychosis}

It may sometimes be difficult to distinguish OCD from an overvalued idea, especially if the belief has been held for some time and resistance has disappeared. An overvalued idea is considered to be reasonable (versus futile), natural (versus intrusive) and not resisted (McKenna, 1984). One needs also to consider whether the OCD symptomatology represents a defence against either an acute psychotic breakdown or a more gradual deterioration of personality.

\section{Treatment}

OCD is a chronic condition; if the symptoms have been established for more than a year spontaneous recovery is unusual. Given that it takes most individuals many years to present for treatment, there is much unmet need in the community from OCD. One of the challenges for the mental health professional is to make sufferers aware that effective treatments are available and how these might be accessed. Controlled research has identified two treatments as being effective for OCD - behaviour therapy and pharmacotherapy.

\section{Behaviour therapy}

Successful behaviour treatment of OCD was first developed in the mid 1960s by Victor Meyer (1966). Initially, it was both lengthy and expensive as it involved therapist-assisted exposure. This has now been shown to be unnecessary and treatment time has been reduced to $10-15$ sessions, making it potentially available to many more individuals (Marks, 1991).

The principles of this treatment are extremely simple. The patient has to expose himself to the anxiogenic cue and thereafter resist the undoing ritual. Thus, someone who is fearful of contamination would, as part of their treatment, deliberately contaminate themselves (exposure) and then resist the compulsion to wash (response prevention). Someone who is compulsively neat would be expected to leave their possessions in disarray and then resist the compulsion to tidy them and so on. The essential manoeuvre of the treatment is that the behaviour should generate anxiety which must then be tolerated in the absence of the undoing ritual.

Controlled research has shown that if the therapy is practised in a systematic manner, then it is successful in most cases. These gains are maintained for many years of follow-up (O'Sullivan \& Marks, 1990). Foa et al (1985) reviewed studies of patients treated with behaviour therapy and concluded that half of the patients achieved a $70 \%$ reduction in symptoms.

\section{Relapse prevention}

Since we know that adverse life events are often associated with a recrudescence of the OCD, the patient can predict the times of future relapse so that appropriate self-exposure and response prevention can be commenced. Short booster courses of therapy, for example one or two sessions, may be necessary to re-establish the previous programme.

\section{Pure obsessional ruminations}

This subset of OCD involves thoughts which intrude into the mind despite, as Henry Maudsley described, 'the most earnest wish to turn and keep them out'. In the past, obsessional ruminations had a particularly poor response to behavioural techniques of thought stopping and distraction

$$
\begin{aligned}
& \text { Box 1. Behaviour therapy for } O C D \\
& \text { Failure to habituate may be caused by: } \\
& \text { Inadequate homework or covert neutra- } \\
& \text { lising } \\
& \text { Co-occurrent major depression } \\
& \text { Covert consumption of anxiolytic drugs or } \\
& \text { alcohol } \\
& \text { Physiological non-habituation }
\end{aligned}
$$


(Rachman, 1983). More sophisticated conceptualisations of this disturbance have improved treatment response. These view obsessional ruminations as comprising anxiogenic thoughts together with anxiolytic or cognitive neutralising rituals which have the same maintaining effect on the rumination as overt compulsive behaviour (Salkovskis \& Westbrook, 1989). Treatment consists of the patient (again as a part of a homework task) recording their anxiogenic thoughts on a loop cassette tape and then playing these thoughts continually until habituation occurs, while at the same time omitting anxiolytic or cognitive neutralising thoughts.

\section{In-patient units}

In the past OCD was thought to be such a serious and refractory disorder that intensive in-patient work was required to effect change. The recent emphasis on self-exposure means that in-patient treatment is rarely necessary. Indications for inpatient treatment have now been refined to include: those who do not have access to behaviour therapy locally; those who have severe OCD or co-occurrent depression, and where members of the family need to rehearse not giving reassurance (Thornicroft et al, 1991). In the main, however, hospitalisation is not necessary and it is likely that gains made in hospital may well be lost after discharge.

\section{Cognitive therapy}

The need for cognitive restructuring in addition to behaviour therapy is not entirely established (Emmelkamp \& Beens, 1991). Certainly, the unwary or inexperienced practitioner should avoid debating the validity of a particular thought or behaviour with an OCD sufferer, as this may offer a subtle form of reassurance. Cognitive therapy may be of advantage in persuading an individual to take the risk of engaging in a behavioural experiment, or in making the thought more egodystonic so that it can be challenged. This especially applies when the obsession has the quality of overvalued ideation (Salkovskis \& Warwick, 1985). Cognitive therapy may also be used to improve compliance, which is a major problem with behaviour therapy.

\section{Treatment failures in behaviour therapy}

Treatment failure in OCD may arise from:

Treatment refusal (5-25\%).

Treatment drop-outs (10\%).

True treatment failures (10\%).

Treatment relapse (20\%).
Thus, of OCD patients referred for treatment and believed to be suitable for behaviour therapy, some 30-50\% will make little progress (Duggan et al, 1993). Foa et al (1985) have investigated some of the predictors of failure in OCD. They identified initial severe depression, late age of symptom onset, pre-treatment anxiety and overvalued ideation as having had a negative effect on outcome. Depression prevented habituation taking place at all whereas with overvalued ideation, habituation took place within but not outside the session. Neither duration nor severity of symptoms affected outcome.

\section{Problems in carrying out behavioural interventions}

To a non-believer in behaviour therapy, it may seem extraordinary that an activity which has been the kernel of the pathology for so many years can suddenly be confronted in such a bare-faced way and that this approach can be so successful. How does the therapist convince and coax someone to take on an activity which had hitherto been avoided so stringently? At the point of assessment, it is essential that the patient recognises that only he can alter his condition and that it is his responsibility to do so. Although many individuals will recognise the validity of the behavioural analysis, this intellectual acquiescence does not mean that they are willing to take a risk with the treatment. To encourage the patient to take this risky step, one can point to the following: although anxiety is uncomfortable, it may well not be as uncomfortable as the patient anticipates; the amplitude and duration of anxiety will diminish over time, and the prediction that something catastrophic will happen may be discomfirmed by the behavioural experiment.

\section{Failures to habituate}

Since habituation is the most crucial aspect of successful treatment it may be helpful to list the reasons for a failure to habituate (see Box 1). By far the most common is that homework between sessions is not carried out satisfactorily. Patients generally underestimate the amount of homework involvement necessary to overcome their OCD. Patients need to spend at least one hour every day practising homework tasks. Records should be made of the homework in a simple diary. Taking homework seriously is as important for the therapist as for the patient. A large proportion of every session should be given over to an examination of the homework diary. This will help identify many potential pitfalls in treatment. These 
Box 2 Drug treatment for OCD - practice points

Only drugs affecting the serotonergic system are effective

Dosage needs to be high (e.g. 250-300 mg clomipramine, $60-80 \mathrm{mg}$ fluoxetine)

Response is slow and may not occur for several weeks

Response to OCD is independent of baseline depressive symptomatology

Relapse is the norm on stopping medication

include: (a) not doing homework at all - which unfortunately is quite common; (b) doing homework, but not systematically or regularly enough to be effective (e.g. only two days out of seven); (c) carrying out an inadequate exposure exercise shown by a low anxiety score, either because the task was not sufficiently anxiety provoking, it was ended prematurely, or some mode of distraction was used.

Review of the homework exercises will focus on: examining the previous tasks since the last session; discussing any difficulties which may have arisen in carrying out the homework exercises and setting homework exercises for the next session. The patient will be setting more and more of the homework tasks themselves in a successful treatment, so that the length of a session can be shortened to the order of 15-20 minutes.

Co-occurrent depression appears to increase the severity of OCD, and to decrease learning and motivation and so must be treated urgently. One needs also to inquire repeatedly into the illicit use of anxiolytic substances. There remains a small group of patients who despite carrying out homework assignments, do not habituate. Unfortunately, they are a group who can only be discovered by default and cannot be predicted in advance.

\section{Pharmacotherapy}

There have been individual case reports of successful treatment with a diverse series of drugs, but the only medications with consistent antiobsessional effects are those which act on the serotonergic system. Controlled evaluation points to the efficacy of clomipramine and more recently, several of the specific serotonergic re-uptake inhibitors (SSRIs). These drugs achieve a significant symptom reduction in 30-60\% of cases (White \& Cole, 1990). Even in cases where there is residual symptomatology, the individual usually regards the reduction as a major benefit (Jenike, 1990).
Clomipramine has been the most extensively studied of any drug prescribed for OCD. Placebocontrolled trials have shown that it is effective, for example the Clomipramine Collaborative Study showed a significant reduction in OCD compared to a placebo control (Clomipramine Collaborative Study Group, 1991).

Several of the modern SSRI drugs (fluoxetine, fluvoxamine and sertraline) have been shown to be efficacious in treating OCD (Chouinard et al, 1990; Goodman et al, 1992). For instance, double blind placebo-controlled studies of fluvoxamine have shown an effect independent of the baseline depressive ratings (Jenike et al, 1990). There have also been encouraging reports of the efficacy of fluoxetine in OCD where, as with clomipramine, high doses are necessary (Jenike, 1990). Although the side-effect profile of these drugs is less than that of clomipramine, they can cause GI upsets, nausea, diarrhoea and motor restlessness. A comparison between clomipramine and fluoxetine by means of meta-analysis showed the former to have the greater effect size but also to have more side-effects (Jenike, 1990). Although the chances of obtaining symptomatic relief are high, relapse is common on discontinuing medication (Pato et al, 1988). The important practice points when using pharmacotherapy for OCD are listed in Box 2.

\section{Treatment resistance}

When the patient fails with a mainline drug, the first step is to switch to an alternative SSRI. After this, the standard medication could be augmented by a range of drugs including lithium (10\% respond), an MAOI, buspirone, tryptophan or neuroleptics, although there are no clear data to support the effectiveness of most of these.

\section{Selecting optimal treatment strategies}

The advantage of behaviour therapy over drugs is that it produces greater overall improvement, which once established, tends to persist (unlike treatment with medication) and, it is cheaper in the long term. The disadvantages are the need for trained therapists to supervise the treatment, a significant involvement at the initial stages to get the therapy underway and, the greater drop-out rate. Since there is no research to inform us on the indications for either of these treatments, selection must depend on patient preference and the availability of trained behaviour therapists.

Assessment of comorbid depression is important as this will require treatment in its own right if 
behaviour therapy is offered as the front-line treatment. Augmentation of behaviour therapy with cognitive therapy would appear to be indicated for an overvalued idea. As other diagnoses are documented in addition to OCD, then it may be possible to develop a rational policy of management for the overall treatment of the patient. Thus, although certain authors argue that there is no role for anxiety management (e.g. Marks, 1991), there may be a role for the same in a subgroup of patients where the anxiety level is so high it either prevents the patient engaging in the task, or prevents habituation. Similarly, individuals with personality disorder and OCD may well require extensive treatment for their personality disorder in order to improve their compliance with a behaviour programme.

\section{Combining drugs with behaviour therapy}

Since neither pharmacotherapy or behaviour therapy for OCD is entirely satisfactory when prescribed singly, is there an advantage in combining these two approaches? Marks and colleagues compared clomipramine and exposure with exposure alone. They found that although clomipramine initially enhanced the effect of exposure, this drug effect had disappeared at two years' follow-up (Marks et al, 1988).

Another combination study by Foa et al (1992) tested the hypothesis that treating OCD patients with an antidepressant before treatment with behaviour therapy would enhance the response to the latter in patients with OCD and severe depression. Contrary to their hypothesis, they found: pretreatment with antidepressants did not enhance the effects of behaviour therapy for OCD (as compared to placebo); the antidepressant reduced the depressive but not the OCD symptoms and behaviour therapy reduced the OCD symptoms. Present evidence suggests therefore, that a behaviour approach used as the primary intervention is a sufficient treatment in itself and does not require adjunctive medication. However, when medication is used as the primary intervention, it is useful to complement it with behaviour therapy to prevent relapse once the medication is stopped.

\section{Psychosurgery}

For those who remain severely disabled with $O C D$ and who have not responded to either medication or behaviour therapy, psychosurgical techniques such as cingulotomy, anterior capsulotomy or modified leucotomy have been shown to have some effect. Jenike et al (1991) recently reviewed the long-term outcome of 33 patients with OCD after cingulotomy. They concluded that $25-30 \%$ had benefited substantially from the procedure. The main side-effects were seizures $(9 \%)$ and transient mania $(6 \%)$. They also suggested that improvement occurs over weeks or months and that conventional treatments which might have failed pre-surgery are well worth trying post-operatively as the response may then be significantly improved.

\section{Summary}

Obsessive-compulsive disorder is a common psychiatric condition with a lifetime prevalence of $2.5 \%$. The basic neuropathology, centring on the orbito-frontal cortex, is gradually being clarified. Behaviour therapy or drugs have been shown to be effective in controlled research.

Behaviour therapy is successful in up to $70 \%$ of cases treated and these gains persist in several longterm follow-up studies. Obsessional ruminations can now be treated successfully with a behavioural approach. Drugs which act to increase serotonin also produce substantial symptom reductions in between $30-60 \%$ of patients, however, relapse is common once the medication has been stopped. Future research needs to focus on unmet need in the community, treatment refusers and the role of anxiety management training.

\section{References}

Baxter, L. T. Jr., Schwartz, J. M., Bergman, K. S., et al (1992) Caudate glucose metabolic rate changes with both drug and behaviour therapy for obsessive compulsive disorder. Archives of General Psychiatry, 49, 681-689.

Beck, A. T., Ward, C. H., Mendelson, M., et al (1961) An inventory for measuring depression. Archives of General Psychiatry, 4, 561-571.

Chouinard, G., Goodman, W. \& Griest, J. (1990) Obsessivecompulsive disorder - treatment with sertraline: a multicenter study. Psychopharmacological Bulletin, 26, 279-284.

Clomipramine Collaborative Study Group (1991) Clomipramine in the treatment of patients with obsessive-compulsive disorder. Archives of General Psychiatry, 48, 730-738.

Duggan, C. F., Marks, I. \& Richards, D. (1993) Clinical audit of behaviour therapy training of nurses. Health Trends, 25, 25-30.

Emmelkamp, P. M. G. \& Beens, H. (1991) Cognitive therapy with obsessive-compulsive disorder: a comparative evaluation. Behaviour Research Therapy, 29, 293-300.

Foa, E. B., Steketee, G. S. \& Ozarow, B. J. (1985) Behaviour therapy with OCD. In Obsessive Compulsive Disorder (ed M. Mavissakalian), pp. 49-129. New York: Plenum. 
-, Kozak, M. J., Steketee, G. S., et al (1992) Treatment of depressive and obsessive-compulsive symptoms in OCD by imipramine and behaviour therapy. British Journal of Clinical Psychology, 31, 279-292.

Goodman, W. K., McDougle, C. J. \& Price, L. H. (1992) Pharmacotherapy of obsessive compulsive disorder. Journal of Clinical Psychiatry, 53, 29-37.

Insel, T. R. (1992) Toward a neuroanatomy of obsessivecompulsive disorder. Archives of General Psychiatry, 49, 739-744.

Jenike, M. A. (1990) The pharmacological treatment of obsessive-compulsive disorders. International Review of Psychiatry, 2, 411-425.

-, Baer, L. \& Greist, J. H. (1990) Clomipramine vs fluoxetine in obsessive-compulsive disorder: a retrospective comparison of side-effects and efficacy. Journal of Clinical Psychopharmacology, 10, 122-124.

-, - Ballantine, M. D., et al (1991) Cingulotomy for refractory obsessive compulsive disorder. Archives of General Psychiatry, 48, 548-550.

Lelliott, P. T., Noshirvani, H. F., Basaglu, M., et al (1988) Obsessive-compulsive beliefs and treatment outcome. Psychological Medicine, 18, 697-707.

Marks, I. M. (1986) Behavioural Psychotherapy: The Maudsley Pocketbook of Clinical Management. Bristol: Wright.

- (1987) Fears, Phobias and Rituals. Oxford: Oxford University Press.

- (1991) Self-administered behavioral treatment. Behavioral Psychotherapy, 19, 42-46.

- \& Mathews, A. M. (1979) Brief standard self-rating for phobic patients. Behaviour Research and Therapy, 17, 263-267.

-, Lelliot, P., Basoglu, M., et al (1988) Clomipramine, selfexposure and therapist-aided exposure for obsessivecompulsive rituals. British Journal of Psychiatry, 152, 522-534.

McKenna, P. J. (1984) Disorders with overvalued ideas. British Journal of Psychiatry, 145, 579-585.

Meyer, V. (1966) Modification of expectations in cases with obsessional rituals. Behaviour Research and Therapy, 4, 273280.

Mulder, R. T., Sellman, D. \& Joyce, P. R. (1991) The comorbidity of anxiety disorders with personality, depressive, alcohol and drug disorders. International Review of Psychiatry, 3, 253-263.

Myers, J. K., Weissman, M. M., Tischler, G. L., et al (1984) Six month prevalence of psychiatric disorders in three communities. Archives of General Psychiatry, 41, 959-967.

O'Sullivan, G. \& Marks, I. M. (1990) The treatment of anxiety. In Handbook of Anxiety (ed M. Roth). New York: Elsevier.

Pato, M. T., Zohar-Kadouch, R. \& Zohar, J. (1988) Return of symptoms after discontinuation of clomipramine in patients with obsessive compulsive disorder. American Journal of Psychiatry, 144, 1543-1548.

Rachman, S. J. (1983) Obstacles to the successful treatment of obsessions. In Failures in Behaviour Therapy (eds E. B. Foa \& P. Emmelkamp), pp. 35-57. New York: John Wiley \& Sons.

Rasmussen, S. A. \& Eisen, J. L. (1992) The epidemiology and differential diagnosis of obsessive compulsive disorder. Journal of Clinical Psychiatry, 53, 4-10.

Salkovskis, P. M. \& Warwick, H. M. C. (1985) Cognitive therapy of obsessive-compulsive disorder: Treating treatment failures. Behavioural Psychotherapy, 13, 243-255.

— \& Westbrook, D. (1989) Behaviour therapy and obsessional ruminations: Can failure be turned into success? Behavioural Research and Therapy, 27, 149-160.

Thornicroft, G., Colson, L. \& Marks, I. (1991) An in-patient behavioral psychotherapy unit: Description and audit. British Journal of Psychiatry, 158, 362-367.

White, K. \& Cole, J. (1990) Pharmacotherapy. In Handbook of Comparative Treatments (eds A. S. Bellack \& M. Hersen), pp. 266-284. New York: John Wiley \& Sons.

\section{Multiple choice questions}

1 In OCD:

a Genetic factors are of considerable aetiological importance

b The condition is often precipitated by adverse life events

c Early presentation is usual

d Males are affected as frequently as females by compulsive washing

e Premorbid personality traits are invariably obsessional

2 True or false:

a Modern epidemiological surveys indicate that OCD is one of the more common psychiatric disorders

b Areas of the cortex implicated in OCD include the cingulate cortex and caudate nucleus

c Relapse is uncommon on cessation of medication

d Behaviour therapy is successful in $80 \%$ of suitable cases

e Drugs used to treat major depression are generally effective in treating OCD

3 True or false:

a Untreated comorbid depression is a common cause of treatment failure in $\mathrm{OCD}$

b Accompanying major depression is a common reason for individuals with $O C D$ to seek help

c A drug and alcohol history is an important part of the assessment

d Drugs that are successful in treating OCD are efficacious because they reduce depressive symptoms

e The presence of insight is necessary for the diagnosis of $O C D$

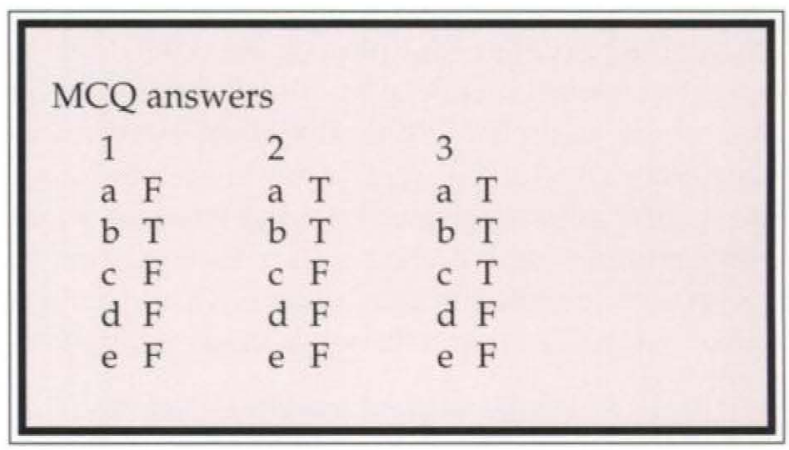

